\title{
3
}

\section{Forbidden from the Heart: Flexible Food Taboos, Ambiguous Culinary Transgressions, and Cultural Intimacy in Hoi An, Vietnam}

\section{Nir Avieli}

Non-Asian tourists visiting the lively market of Hoi An, a town in central Vietnam where I have been conducting ethnographic research since 1998 , are often surprised by the huge array of aquatic and amphibian creatures of shapes and sizes they have never seen before, often sold live, skinned and gutted on the spot. They stare in horror at the slaughtering of chicken and ducks, and the handling of fresh non-refrigerated flesh. They are visibly disgusted by the sale of internal organs such as hearts, lungs, kidneys, guts, claws, hooves, or ears, which are rarely consumed in their countries of origin. A recurrent topic on any market visit is dog meat (which is not sold in Hoi An's markets, and see Avieli 2012a). Visitors seem to be most eager to find what they consider tabooed flesh (such as that of reptiles, amphibians, or dogs), and when they do, they take a picture, stare for a while, and leave disgusted. One comment I have heard repeatedly in such circumstances was that "they eat everything".

N. Avieli $(\square)$

Department of Sociology and Anthropology, Ben-Gurion University,

Beersheba, Israel

e-mail: avieli@bgu.ac.il 
Such comments are hardly trivial. While Mary Douglas (1975) argued that food taboos are important components of any categorization system, Marvin Harris (1987) suggested that they are the rational outcome of material considerations (see also Meyer-Rochow 2009 for a comparative functional approach). Interpretative anthropologists stressed the symbolic meanings of food taboos and their role in reinforcing and/or undermining power relations (Mintz and Du Bois 2002). A social group accused of having no food taboos is actually suspect of complete lack of categorization processes, rational decision-making, social boundaries, and/or moral framework. If "they eat everything", "they" must be uncivilized, savage, and, in fact, cultureless.

Food taboos are usually understood as rules that should never be lapsed (Lien 2004; Meyer-Rochow 2009), and when transgressed, cause inevitable pollution and call for retribution and ritual purification (Douglas 2003 [1966]). Many years of studying foodways and food taboos in different cultures lead me to the understanding that such notions of taboo as a total prohibition are not universal but, rather, culture specific. In fact, the idea that specific foods, or as is most often the case-the flesh of specific animals, is completely forbidden and should be avoided under any circumstances, is found mostly in cultures where monotheism prevails. $^{1}$

Indeed, the term taboo, originally tapu in Tongan language, introduced into English by James Cook in the late eighteenth century, "has been the source of much scholarly analysis ever since, but the logic behind a word that can be applied to many disparate and apparently contradictory things continues to puzzle the scholars" (Shirres 1982: 29). Shirres points out that tapu "can be applied equally to high descent, ritual and sacred lore, and to death, darkness menstrual blood and filth", associations which make sense for the Maoris, but "has eluded scholarly [Western] analysis" (Shirres 1982: 29). Gilmore et al. (2013: 332) point out that "taboo commonly [in English] refers to things which are culturally proscribed for symbolic rather than pragmatic reasons ... Tapu, however, is a much more complex concept which, in Polynesia, is intrinsic to a cultural worldview which places people, objects, places and activities under the protection of the atua [gods, spirits] and, therefore, as sacred, or apart from the ordinary". So, when the term "taboo" was adopted into common 
usage in the English vocabulary and as an important anthropological term, it was preloaded with misunderstandings regarding its meaning and cultural function: rather than "total prohibition", its original denotation had to do with sacredness and uniqueness (Gilmore et al. 2013: 336; Calder 1999; Sachdev 1989).

In Vietnam, where âm duóng (Chinese Yin-Yang), completingoppositions that maintain a dynamic balance, govern the cosmos and everything within it (Jamieson 1995; Avieli 2012b), and where the unity and oneness of God are hardly the rule, food regulation and temporary restrictions are common (Manderson and Mathews 1981; Mathews and Manderson 1981), but total food prohibitions rarely exist. Indeed, though Manderson and Mathews (1981) use the term "food taboos" in the introductory parts of their articles, when it comes to the culinary practices themselves, they describe temporary prohibitions and restrictions during pregnancy and post-labor. Thus, their findings too suggest that in Vietnam, food restrictions are context dependent and temporary, in line with the Polynesian idea of tapu rather than the total prohibition implied by the Western notion of taboo.

Buddhism does call for total avoidance of animal products due to the compassion that must be cultivated toward all living beings, yet only a few Hoianese (and for that matter, relatively few Buddhists elsewhere) practice complete veganism. What is very common in Hoi An is parttime veganism: "full moon" and "black moon" (ngày rằm and mùng một) veganism or other temporal patterns of animal-flesh avoidance. Elsewhere (Avieli 2014) I elaborate how such patterns of temporal veganism are adopted by increasing numbers of Hoianese as a consequence of - and an antidote to-modernity. The important point, however, is that meat avoidance is considered by most Buddhists as a temporal restriction rather than complete and total prohibition. Here again, tapu rather than taboo is the organizing principle.

Buddhism further advocates abstinence from "ten forbidden meats": human, elephant, horse, dog, snake, lion, tiger, leopard, bear, and hyena (Tambiah 1969). Yifa (2002: 56) mentions "dragon" too-an idea to which I return shortly. Thus, despite the call for complete veganism, Buddhism actually acknowledges the fact that many adherents do eat the flesh of living creatures, and sets further prohibitions regarding the flesh 
of the specific animals mentioned above. In this sense, Buddhist meat prohibitions are relative and fluid. Here again, my Hoianese interlocutors adhere to these prohibitions only to a certain extent and would be willing and even eager to gorge over most of these meats during certain times and in specific contexts, and abstain in others.

"We do have one total food taboo", pointed out one of my most knowledgeable friends, "dragon meat is taboo!". When I asked her to elaborate, she explained: "dragons have alligator-heads, snake bodies, fish scales and parts of many other animals. We can eat alligators, snakes and fish, but not dragons." This remark is the exception that makes the rule: Vietnamese do follow a total food taboo, but only when it comes to the flesh of an animal that does not exist (or, perhaps, whose flesh is unavailable). This remark is extremely important as it exposes the ambiguous approach to total food prohibitions in Vietnam: the principle is acknowledged, but the actual culinary practices are flexible.

In this chapter I discuss culinary establishments that specialize in the flesh of animals that should be avoided in Hoi An, at least in principle: he-goat meat (thit dề) and jungle meat (thit rừng), and their complex relations with the taboo on "eating human flesh" (ăn thit người). Some Hoianese, mainly male members of the emerging middle class, may gorge on jungle meat and he-goat meat in specific circumstances in the context of increasing affluence, modern consumerism, and class distinction. Eating these meats expresses wealth and sophistication. Food venues that serve these meats mainly attract groups of men, some in the company of their female mistresses or lovers, but not their spouses and children. These venues also offer hostess services, which may include paid sex. These culinary spaces are therefore arenas for the performance of hyper-masculinity, associated with excessive drinking, smoking, potency, and illicit sexuality.

Many of my Hoianese friends, women and men, were critical of these food venues and the culinary transgressions they entail when discussing them in public. However, male and some female interlocutors who admitted in private to frequenting such restaurants were clearly ambivalent. They were excited yet ashamed at partaking in what they themselves described as repulsive, illegal, and, perhaps, immoral culinary practices that expressed gluttony, greed, violence, lust, and unfaithfulness. Desire 
and fear were often mentioned concomitantly when discussing these preferences and when dining at these restaurants. Along the chapter, I point to the social components that underlie this ambivalence.

In order to make sense of these Hoianese flexible food taboos, I conclude by drawing on Michael Herzfeld's concept of "cultural intimacy". Cultural intimacy is "the recognition of those aspects of a cultural identity that are considered a source of external embarrassment but that nevertheless provide insiders with their assurance of common sociality ... This can take the form of ostentatious displays of those alleged national traits ... that offer citizens a sense of defiant pride in the face of a more formal or official morality and, sometimes, of official disapproval as well" (Herzfeld 2005: 3).

While Herzfeld emphasizes relations with the state and its officials, I show how cultural intimacy may also be experienced among members of specific social echelons in their relations with members of other social groups. In this sense, flexible food taboos and ambiguous culinary transgressions, despite their explicit negative image, are perceived positively by the practitioners, at least to a certain extent. However, such transgressions and the ambivalence they entail involve a measure of anxiety that seems to spice up the food and make it uniquely palatable.

\section{Quán Nhậu (Rice Liquor Shops): Sites of Transgression}

Places that serve he-goat meat and jungle meat in Hoi An belong to the culinary category of quán nhậu (liquor shops): drinking establishments where men consume alcohol and duong (yang) charged dishes, made with ingredients and spices that are considered warming (nong) and libido enhancing (basically animal flesh seasoned with ginger, garlic, and chili, fried and/or rich dishes). In the late 1990s, there were only a few quán nhâu in Hoi An. The most common places where men would drink alcohol were dingy makeshift sheds set in back alleys serving cheap rice alcohol (rướu gạo) or beer and chicken or duck rice gruel (cháo gà and cháo $v i t$ ), mainly to blue-collar men. Most of my Hoianese friends, members 
of the tourism-related nascent middle class, avoided these venues, and the common explanation had to do with the drunkenness of the patrons as well as the coarseness of the food and setting. Male drunkenness was presented as violent and dangerous, especially for women. These culinary establishments were avoided also by those who could afford more refined dining options and locations.

These venues, just like the more elaborate restaurants with which I deal in this chapter, were operated by women. I ate at some of them and observed what I later realized were the general patters of men-to-men and men-to-women interactions in culinary establishments that involved libido and masculinity enhancing foods, excessive consumption of alcohol, and a measure of social competition. Drinking entailed increasing (or escalating) tensions: competition and challenge among men, which led at times to actual violence; and sexual tension and desire harbored by the men toward the women who operated the stalls. These women were clearly very experienced in handling their clients, making sure that the men paid for their food and drink while keeping them at bay; at the same time-some measure of feminine interest and attraction, or at least, some exchange of sexually charged semi-joking comments were part of the service. As far as I could tell, these were essentially professional maneuvers by the female owners intended at attracting and maintaining male clientele.

While drunkenness was criticized by almost every Hoianese with whom I discussed this issue, male binge drinking (easily discerned in the flushed faces of the drunk men) was the rule in all major social/ritual gatherings, ancestor worship events, and weddings, and was clearly tolerated by all those present. As tables in such events were gender segregated, most of the drunk interaction was among men, who turned increasingly competitive and abusive the more they drunk. Nasty comments were sometimes exchanged, and wild bursts of laughter became at times angry and abusive. In some cases, drunk men would become violent, but since they were so drunk, this never resulted in more than attempted punches and perhaps a turned-over table. These drunk men were easily overcome by somewhat less drunk companions, who would drag them away.

As public violence was so rare in Hoi An, I was surprised and intrigued when I witnessed such incidents early in my fieldwork. I was surprised by 
the violence and intrigued by the setting: though overt violence was very rare in daily public interactions and spheres, it was almost expected in important social rituals, which seemed to me completely inappropriate spaces for such transgression. When I inquired about this public display of what I felt was total breach of proper social conduct, these public acts were dismissed as unimportant. I was told that these men were drunk, which made their lack of control negligible and tolerable. I gradually realized that the expression and containment of drunkenness and violence in public events was an elaborate mechanism that allowed the articulation of negative sentiments in public, specifically among relatives and friends, while defining them as petty and insignificant.

Rising incomes set the ground for the proliferation and popularity of ever more sophisticated quán nhâu that offered beer and even imported (or at least bootlegged) alcohol and increasingly more elaborate and exotic dishes. Many of these new places specialized in fish and seafood, while others served the expensive animal flesh attributed with virility, strength, and sexual potency, such as he-goat or that of wild animals. The virility and potency embedded in the flesh of these animals was further exacerbated by the nóng (hot/piquant), libido-enhancing spices such as chili, lemongrass, ginger, and rau răm (Vietnamese coriander).

McNally (2003), Nguyen-vo (2008), and Horton and Rydstrom (2011) address similar establishments, termed karaoke ôm ("hugging karaoke"), where "girls serve food and drinks to customers, select the songs that they wish to sing, and allow the men to touch, hug, and kiss them" (Horton and Rydstrom 2011: 552), suggesting that these venues were practically brothels. While karaoke ôm are extremely common in Vietnam, the local authorities in Hoi An have been very effective in curbing them. Quán nhậu differ from karaoke ôm in their emphasis on food and drink rather than karaoke, and in the sexual tone, which is less pronounced.

One of the outcomes of the increasing affluence in Vietnam, and of the booming tourism industry in Hoi An during the last two decades is the emergence of a new socioeconomic elite, composed mostly of successful business people, as well as high ranking government employees and officials who manage to get a piece of the economic cake, legally and illegally. Many of the members of this new local elite are deeply involved 
in conspicuous consumption and use their newly acquired means so as to celebrate and enhance their status. The more affluent purchase cars (rather than the ubiquitous motorbikes), travel to ever more remote and expensive destinations abroad, build large mansions and villas with luxurious gardens and pools, and send their children to overseas schools and universities. Bearing in mind that cars, villas, overseas schooling, and expensive trips abroad remain too expensive for most members of the Hoianese expanding middle class, they tend to invest their newly acquired capital in branded motorbikes, large houses, trips to Southeast Asian countries and universities for their children in Hanoi and Saigon and, perhaps, Singapore.

They are also eager to try new and exotic food in ever more refined settings, hence the flourishing and upgrading of quán nhâu. One version is that of restaurants that are set in simple, even coarse setting, but serve high-quality food cooked to order, along with beer and other alcoholic drinks, inclusive of ruợ gạo. A more upscale version is that of open-air garden (vüơn) restaurants, located at the margins of town, overlooking countryside, river or beach scapes, serving expensive, rare, power, libido and status-enhancing dishes accompanied by local and imported alcoholic drinks. While the cheaper quán nhạu were, and still are, a male-only affair, these new culinary establishments attract couples and even whole families, who uneasily share the culinary space with a majority of maleonly groups, often drunk, loud, aggressive, and rude. These establishments, like their less sophisticated predecessors in the late 1990s, are mostly owned and managed by women, and employ female waitresses. The new garden restaurants are also mostly female-run, though many are family businesses, with male family members involved in the operation.

One prominent aspect of contemporary quán nhậu is the employment of gái bia (beer-girls). These women are employed by the beer companies and not by the restaurants, and are paid commission for the beer they sell. They are provided by the beer companies to the restaurants for free. However, as the beer-girls' income depends on the amount of beer consumed rather than the food eaten, they "push" beer rather than food, hence the structural tension between the restaurant owners, who are eager to use free manpower but boast and profit from the food they cook (Avieli 2012a). The beer-girls usually dress in very daring and sexy outfits, 
at least by Hoianese standards, wear heavy makeup and offer a variety of services to their male costumers beyond the actual serving of food and drinks: they pour the drinks, light cigarettes, wipe the customers' faces with cold towels, feed them, and even sit on their laps. They often drink and smoke with the clients, flirt with them, and allow different measures of physical contact. At least some of them engage in paid sex, while others double as kept mistresses. Gái bia are considered in Hoi An a notch above gái ôm ("hugging girls" or sex workers). Arguing that someone is a gái bia is a serious insult and admitting that one's relative is one is very embarrassing.

Women, be it beer-girls waitresses or lovers, have a pivotal role in the process of masculinity enhancement that takes place in quán nhâu: they encourage the consumption of dưong (yang), nóng (warming) dishes, and alcohol and excite their clients with a combination of feminine submission (lighting cigarettes, wiping sweat, using respectful female grammar, and childlike, high-pitched tone) and assertive sexuality (dressing daringly, drinking, smoking, and flirting). These women are also the target of the resulting excessive masculinity: they allow their clients different measure of physical contact and, ultimately, if having sex with them, literally incorporate the excessive duong (male energy), serving as receptive utensils into which this excess is ejaculated.

\section{Meat, Spiciness, and Masculinity}

While all quán nhậu are spaces where men drink, consume dưong foods, and engage in sexually charged extramarital relations, all of which are social transgressions, they do not necessarily entail culinary transgression. The flesh of fish, seafood, chicken, pork, and at times beef, served in these restaurants is not forbidden or otherwise frowned upon. In fact, these are the kinds of flesh commonly eaten at home, in public, and ritual meals. What makes the food served in such establishments different and masculine (besides the excessive consumption of alcohol) is the relatively large amounts of animal flesh (when compared to home eaten meals), and the nóng (hot/piquant) seasoning, which differs from the balanced, delicate seasoning common in Hoianese home cooking. 
Scholars researching the interface of food and culture have long emphasized the strong links between meat, physical power, social dominance, and masculinity. Nick Fiddes (2004: 65) argues that eating meat is, above all, symbolic: "Killing, cooking and eating other animals' flesh is the ultimate authentication of human superiority over the rest of nature", while Carol Adams (2015) reminds us that the British Royal Guards are called "Beefeaters" because of their food of choice, designated to ensure their physical strength as members of a crack unit (that should be "as strong as oxen"), as well rewarding them with high status food, otherwise reserved to the upper classes.

Meat eating also represents socioeconomic and political power. In his classic article on "political types in Melanesia and Polynesia", Sahlins (1963) argues that pork sharing in public feasts constitutes a key physical and symbolic resource in the political game. Far from being exclusively an act of generosity and cooperation, he shows that meat is also a token in the social competition over status and prestige. Twigg (1983: 21) suggests that "meat is the most highly prized and culturally significant of foods", while Elias (1978) shows how in Medieval Europe members of the higher classes ate prodigious amounts of meat, while peasants ate very little of it, if at all. Bourdieu (1984) too argues that meat is indicative of economic wealth and high social status, and that eating certain kinds of meat is a symbolic action that expresses economic, cultural, and symbolic capital.

Eating meat is clearly a gendered practice. Michael Herzfeld (1985) describes how meat is central to the meal of every Cretan who considers himself a man, while Twigg (1983) suggests that the blood that gives red meat its color is expressive of power, aggression, passion, and sexualityattributes that are desirable for men but considered offensive when it comes to women. Willard (2002: 112-113) thus concludes: "Because physical power is historically associated with masculinity and virility ... meat has been perceived as a masculine subject."

Feminist critiques such as Twigg (1983) and Adams (2015) suggest that specific symbols related to meat are situated in a concentric hierarchy: culture above nature, humans above animals, and men above women. While Twigg (1983) suggests that the association of vegetarian and dairy 
foods with femininity indicates weakness and passiveness (as in the use of the term "vegetable" so as to describe a comatose person), Fiddes (2004: 210) argues that "meat exemplifies, more than anything, an attitude: the masculine worldview that ubiquitously perceives, values and legitimates hierarchical domination of nature, of women and of other men". Collectively, these scholars point out that there is no biological or nutritional connection between meat and masculinity. Rather, it is the violent act of asserting one's power and privilege by the killing of another creature and consuming its flesh that makes meat so appealing to men, not the actual building of a strong and muscular body.

When it comes to spiciness, its association with masculinity is not as clear. Herzfeld (2009: 191), in a text that celebrates culinary ambiguity, notes: "it is always tempting to associate high spice with an ideology of masculine pride ... [Indeed] the appearance of an intense spice quickly develops into a test of masculinity, while women claim to be horrified by the very idea of eating anything so spicy. But there is no necessary biological connection between spiciness and masculinity and it is not clear that such connections are found in all human societies." Herzfeld's ambiguous text therefore suggests that spiciness is associated, at least in Thailand, with working-class masculinity. Spiciness, like meat, have very little to do with the biological aspects of masculinity. Clearly, it is all about competition and the demonstration of bodily control that make spicy food masculine, at least in Thailand.

In Hoianese homes, food is rarely spicy, though diners may add (or bite into) hot chili. Spicy food as such is usually served only in quán nhâu $u$, which up until recently served only working-class men. Thus, just like in Thailand, spicy food was associated with working-class masculinity. It should be noted, however, that most members of the Hoianese elite and middle class grew up in working-class families and their taste and habitus are those of the working class, despite their recent affluence.

While spicy food and large amounts of meat are considered masculine in Hoi An, it is the establishment, quán nhậu, along with the social relations it entails, that induces a sense of transgression. Let us now turn to the flesh of specific animals considered forbidden, or at least, inappropriate: he-goat and jungle meat. 


\section{He-Goat Meat}

A group of Hoianese friends with whom I used to have lunch every now and again often played a food/word game that, at first, I couldn't figure out. One of the diners would pick up a morsel of food, say a piece of rau muống (water morning-glory), and ask: "ăn rau bổ gi??" ("[when] eating greens/vegetables, what gets nourished?"). After a short reflection, one of the co-diners would reply: "ăn rau bổ râu!" ("[when] eating vegetable, [the] beard [is] nourished!"), and everyone would burst in loud laughter. After a while, another diner would pick up a different food item, say a shrimp, and ask: "when eating shrimp, what gets nourished?" The answer would be: "when eating shrimp, the shrimp is nourished" ("ăn tôm bổ tôm!”), stirring yet another burst of laughter. Things could get even more incomprehensible, as when someone would ask: "when eating shrimp, what gets nourished?", to which the answer would be: "when eating shrimp, the banana is nourished!" (“ăn tôm bổ chuôi!?).

As my language skills improved, I realized that this confusing food/ word game was actually very sophisticated and had an erotic/sexist undertone, which was well known to the participants and the reason for their laughter: each bite of food insinuated a sex-related body organ. The word rau, which means "vegetable", was replaced by râu, which means "beard" but is also used for body hair and for pubic hair. The meaning of the sentence was: when eating greens, the pubic hair is nourished. Tôm (shrimp), my friends explained, represented the vagina due to its curvilinear shape. However, when eaten by men, it nourishes their "banana" or penis. I also learned that when sữ chim or "bird's milk" was offered, usually by one of the men to either of the women, he was actually referring to semen and was thus suggesting oral sex, as chim, or "bird", is commonly used for the penis. Another double-edged invitation would be to eat "clams" (nghêu), which stand for the vulva.

Thus, while having lunch, these friends were conducting an anatomically detailed conversation about sex, using only food terms, demonstrating the Vietnamese ability to maintain virtuous and chaste façade despite the great interest in, and practical engagement with sex-both within and beyond marriage. This was summarized by a female friend, merely 18 at the time, who realizing my surprise at the juicy piece of gossip she 
shared with me about a mutual friend who was apparently having a very sexually active affair with a married partner, commented: "Nir, we have everything in Hoi An, but quietly".

But this tendency to maintain sexual discourse quiet or camouflaged had one salient exception: goat meat restaurants. When it came to these food venues, things were much more explicit and direct—thit dê (goat meat) was an aphrodisiac and men would dine in places that specialized in this kind of meat as a way of enhancing their sexual potency.

Coming from the Middle East, where goat meat is quite common but hardly an aphrodisiac, I was intrigued by the idea that the meat of this specific animal was attributed with so much libido. Indeed, the word dê or "goat" is routinely used in Hoi An for "horny" (and note the connotation to the he-goat horns in English too ${ }^{2}$ ), and one's 35th birthday (which I celebrated in town) is termed ba lăm dê (35 [years old] goat—in reference to the Vietnamese zodiac) is the source of endless jokes about one's state of sexual arousal. When I wondered why goat meat was considered such a powerful aphrodisiac, a friend explained: "have you ever seen goats in the mountains: there are some forty or fifty female goats and a single he-goat. This male goat may mount any of the females any time, and can actually do it." The he-goat condition was therefore described as ideal from the male perspective: a very large number of available, submissive (and perhaps interested) females; no competition with other males; and no less important: potency to engage in unlimited number of sexual intercourses. This perception depicts the he-goat as the essence of masculinity.

Hoianese Goat meat restaurants, like all quán nhạu, were essentially drinking places. However, they were attributed with specific kind of aura and/or sleazy character: men who frequent these venues were explicitly seeking sexual potency. I asked several friends, men and women, to eat in one of these places but my invitations were all declined with a surprised frown. Eventually, an Australian female tour guide who spent months in town told me that she was craving for mutton and we went for goat meat instead. We came quite late for dinner, and there was only a single man eating alone by one of the tables. This in itself was quite unusual, as in a small town such as Hoi An, meals are very rarely eaten alone, even when one goes alone to the restaurant: there are always people around with who to share the table. 
We ordered roast goat meat by the weight, and spent the evening chewing the tough stringy meat. We were surprised to find out that despite the universal refusal of our friends to frequent this place the actual practices were so innocent (at least during that evening).

A few months later, a friend who was an alcoholic and used any excuse to drink, overheard my questions about goat meat and suggested that my wife and I join him and his spouse for a meal at a goat meat place he knew on the way to Da Nang. His wife was first angry and reluctant, arguing that he was just using a pretext as an excuse to drink, but he used a combination of smiles, soothing voice, and seduction-arguing that this was a rare chance to try goat meat, and that the place he knows serves very tasty dishes, and eventually she half-heartedly agreed.

A few days later we drove to the restaurant. We arrived by late afternoon, just in time for early dinner. The restaurant was a small place of some four tables in the first floor of a family house. A skinny goat was tied by the door on the pavement, serving as a commercial and a proof of authenticity and freshness. We ordered lẩu dê (goat hotpot) and the proprietor asked whether we wanted red or white wine. This was an unusual offer in the early 2000s, when wines were rare and expensive, and hardly a routine component of a meal at a restaurant that catered to low-income clients. My friend explained that "red" was rice liquor mixed with fresh goat blood, while "white" was the same liquor in which the goat testicles were soaked. He ordered glasses of "white" for both of us, but not for the women, and when I declined-drunk mine as well.

We cooked the thinly sliced goat meat in goat-bones broth served in a hotpot, with our friend consuming several beer bottles. His wife was exceedingly distressed and upset, both because of his drinking and because the group of men that occupied another table made offensive comments about her and about my wife. The scene became increasingly uncomfortable and we were relieved to leave. We never experienced this kind of abusive attitude in a restaurant previously, and though such behavior may be tolerated when it comes to drunk men, this was probably one of the most aggressive reactions toward women I have experienced in Vietnam. It was clear to us that the setting - that is, a goat meat restaurant, was a place where such behavior may occur, as it never happens elsewhere. 
I partook in goat meat meals in two other instances that further complicated the sense of transgression and ambiguity surrounding this meat. Not very long after the meal in Da Nang I traveled to visit a friend in Hanoi. I asked my host and her brother to go for goat meat. They took me to a very large and busy restaurant where multi-generational families and large groups of men and women were roasting goat meat over charcoal grill built into the table. When I commented that in Hoi An goat meat is a male-affair, my hosts were surprised. They said that in Hanoi goat meat is considered a specialty and served in specific restaurants, but is not considered masculine or an aphrodisiac. Moreover, though drinking in Hanoian goat meat restaurants was common, these venues were not associated with illicit or paid sex. In fact, my hosts pointed out, one delicacy served in Hanoian goat meat restaurants was goat udders. Along the meal, I realized that the udders were, once more, a subject of double speak and laughter, but this was clearly focused on the notion of udders as a form of female breats $(v u)$. In Hanoi, I realized, goat meat was a special food, but was not associated with explicit masculinity and sexuality but, rather, with femininity and the consumption of the human female body. The transgression here had a somewhat different meaning, but was associated with power relations and sexuality, though the composition of diners (women, children, families) implies more implicit eroticism of the meal.

The forth goat meat meal took place under very different circumstances. An Indian restaurant was set up in Hoi An, and we invited our Vietnamese teacher along with three of her colleagues, two female teachers and a male teacher, to try this new place and experience the new food. Wrongly assuming that our guests were unfamiliar with Indian food, I suggested that I would explain the menu and order the food. I picked some starters and bread, and suggested several vegetarian dishes as main courses, but the male teacher asked if we could have cà ri dê (goat curry). I was surprised by his request, as I never had goat curry in India or in Indian restaurants elsewhere (though I did eat mutton curry). I responded that I didn't think the restaurant served $c \grave{a} r i d \hat{e}$, but the male teacher insisted it did—and was right. We ordered the goat curry and though our guests were quite cautious and ambivalent before and after tasting the goat curry, this dish was clearly the one all our guests, male and female, were interested in. 
Here I should add that the male teacher was a notorious womanizer. Whenever I met him in public, those present at the meeting would tell me later about his intimate relationships with his (high school) students. They were very critical of him not only because of the students but also because they felt angry and ashamed by the way he treated his wife, who was well aware of her husband's exploits, and was hurt and upset. I was told several times that he was dê (goat, i.e., horny), and between me and my teacher, we nicknamed him "Mr. dê”. Oddly enough "Mr. dê" insisted that we ordered cà ri dê. It was also odd, however, that the female teachers, his spouse included, were all eager to try the dish. My understanding was that this was a chance to try this kind of meat in a setting that was socially acceptable or, at least, not male and sex oriented, but rather a place that offered exotic and odd food, where everyone could pretend that no transgression was going on. The event, however, became tense once we ordered the goat curry, with our guests becoming quiet, carefully biting into the goat meat and looking at each other with what seemed to me a combination of fear and embarrassment. The tension eased only once the main course were cleared and we turned to order desserts.

My experience with goat meat in these different settings suggested that this was one salient example of ambiguous culinary transgression. In Hoi An, goat meat was attributed with male potency. It was served in specializing restaurants that catered to men. The meat was either roasted, condensing and augmenting the potency it embodied, or cooked in a broth that ensured that every bit of it was consumed to the fullest. Goat blood and testicles, the essence of its masculinity, were consumed in rice liquor, further increasing the potential masculinity consumed by the diners. Restaurants that served goat meat catered only to men and any woman present was perceived as a legitimate target for sexual approach, exploitation, and abuse, as we realized when such comments were made at our female companions.

Goat meat was perceived by my Hoianese friends as tempting yet problematic. Men were eager to consume it so as to enhance their masculinity. Yet both women and men agreed that this was not the fare appropriate for normative people under normal circumstances. Women were especially critical and deterred from goat meat and the places that served it, but they too were willing (perhaps eager) to try it 
in circumstances that somehow removed the meal from the realm of blunt male potency and sexuality, such as the Indian restaurant.

In Hanoi, goat meat was considered a specialty, but not a blunt vessel of masculine sexuality. In fact, female-goat udders were highlighted, while the testicle-liquor was not offered. The udders were related to female sexuality, but the mixed clientele and multi-generational families suggested that these were respectable (or at least acceptable) dining venues.

Ambiguity was most clearly observable in the Indian restaurant. This place catered mainly to foreign tourists, and was not marked as masculine and/or inappropriate for women. Thus, I could invite four teachers from the town's only high school, all of them well known in town, to have a meal at this food venue. But precisely because this was a tourist-oriented establishment and was not considered locally as a goat meat venue, with all the negative implications such definition entails, the male teacher could ask for goat meat in the presence of his female colleagues inclusive of his wife, while the female teachers, who would otherwise refuse to dine in a goat meat restaurant, were quite enthusiastic to try it. Goat meat in Hoi An was both repulsive and appealing, shunned in public, but thought after by men, and in some contexts, by women. Eating goat meat was a transgression, but one which many Hoianese wanted to experience.

\section{Jungle Meat}

Jungle meat (thit rùng), the flesh of animals hunted in the forest and the wild (or whatever is left of it in Vietnam), is also served in quán nhâu style establishments and is associated with masculinity and male competitiveness, alcohol, beer-girls, and sex. But while goat meat is consumed because of the he-goats' alleged potency, jungle meat is associated with sexuality somewhat less directly. Forest animals are thought-after because their flesh is imbued with the power of the wild. I was told that snakes and other reptiles such as large lizards (con ky dà) may enlarge penis size and strengthen erection because of their shape. Deer is associated with erection because of its long straight horns. Other forest animals, such as the tiger, are consumed because, just like the he-goat, they demonstrate outstanding sexual abilities. But generally speaking, wild animals are 
strong and wild and consuming their flesh would make the eater stronger and wilder. Eating the flesh of such wild animals also expresses the subjugation of nature. Jungle meat is therefore associated with wilderness and untamed power, and with the taming of this power.

Another important feature of jungle meat has to do with the fact that most of it is hunted and traded illegally. Men who eat jungle meat defy both nature and culture: they overcome the wild animals and consume their power, while ignoring the law and the social order. It is hard to think of a blunter statement of masculine confidence and power.

One important aspect of jungle meat restaurants is that the killing should be done on spot and in full view of the clients. The violent ritual of public killing, which often involves draining the blood (and at times the gall) into rice alcohol for immediate consumption, further enhances the sense of power and taming of the wild associated with jungle meat meals. Hoianese jungle meat restaurants therefore display some of the animals whose flesh they offer in cages, and the customers witness the slaughtering.

Killing the animal on the spot also allows clients to observe that the promised meat is not only fresh but also what they paid for. Jungle meat is rare, expensive, and illegal, and I was often told how these restaurants substitute the meat of wild animals with that of domestic ones, which is abundant, cheaper, and legal. Some substitutes are symbolic and even acceptable and declared, for example, serving cat meat instead of tiger (at times under the nickname of "little tigers" domestic pork is served instead of boar. But at times, any cheap and available meat would substitute any promised jungle meat. Killing and cooking the animal in front of the costumers reduces, at least to a certain extent, the potential for cheating.

At the same time, taking part in an illegal activity, even if only by ordering the meat and watching the killing, exacerbates the defiance of the law and thus spices up and invigorates the transgression and the power it entails: here I stand in front of everyone and in broad day lightbreak the law; I am scared of no one.

I found this public defiance of the law especially intriguing because whenever I attended a jungle meat restaurant in Hoi An, some of the clients were public officials, along with their friends, colleagues, and 
business partners (the latter actually paying for the meal, drinks, and hostess services). The jungle meat meals I observed were therefore events in which law makers (politicians) and law officers (policemen) ritually and publically broke the law they were charged with upholding and enforcing.

Since in many cases those paying for the meal were potential partners for illicit or corrupt deals, my understanding is that the meal, alcohol, and sex paid by the hosts were not only a direct form of bribe but also a conduit to future relations: the co-diners were breaking a relatively unimportant law together, creating bonding, trust, and mutual dependency that would stabilize ongoing cooperation.

While I never shared a meal with corrupt officials, my interlocutors described these culinary events several times, shifting from condemning attitude toward the official corruption, to the description of their own pleasure during these meals and accompanying activities. They made it clear that they felt blackmailed by the officials, who made them pay for the expensive food and services in return for things such as licenses and permits, which they were entitled too in any case, or for things that were clearly illegal, such as the postponing of military draft. In most cases I was told that they did not like the company of the officials themselves who were greedy and took advantage of their position. But when I asked about the food, they often commented that it was very delicious. In some cases, they also mentioned that the food had an impact on their libido and their sexual relations with the beer-girls. The comments about the good food and sexual relations were often followed by inviting me to join such a meal. I was first confused by this shift: how was it possible that they felt blackmailed and yet enjoyed the food, drink, and sexual services so much? And why would they want to repeat this experience with me? I gradually realized however, that this combination of shame, guilt, and pleasure was very attractive, and that one way of dealing with the negative aspects of shame and guilt was by arguing that everyone (i.e., all men) take part in such practices. I was invited to join in to not only share the pleasure with me but also the shame and guilt-share the burden as it were and relieve my friends of some of it.

An invitation to dine at a jungle meat restaurant (and to a lesser extent - at a goat meat restaurant) is therefore an invitation for male 
bonding reinforced by partaking in activities that are both illegal (hunting wildlife is banned) and morally problematic (overindulgence, drunkenness, and extramarital paid sex).

Following my working rule of "accepting every invitation" (Avieli 2012b), I never refused an invitation to join in a jungle meat restaurant or jungle meat meal cooked at home, though I generally prefer to stay away from illegal activities, and despite my objection to wild life hunting. I also found it very hard to eat the flesh of animals whose death I witnessed.

This turned out to be awkward: joining the table but avoiding the meat was not merely a refusal to "break bread", but also abuse of the trust bestowed upon me by my hosts. They allowed me to observe them breaking the law and transgress moral standards, but my refusal to eat the food and embody the transgression, as it were, meant that now I had potentially implicating information about my hosts, but since I did not partake in the actual eating, they did not have the same kind of implicating information about me. My hosts were therefore adamant that I eat or, at least, try the meat, and were visibly upset when I refused.

This dynamic was also common in cases were hostesses and potential paid sex were involved. Engaging in paid sex is perhaps the least kept secret of Hoianese men. The subject would come up in many male-only conversations and meetings, usually as a joke or a comment. But if I wouldn't protest or otherwise signal reservation, the conversation would very quickly turn into straightforward discussion of the potential of the waitress or some other women as a sex partner. This would often develop into an ambiguous invitation to pursue sex. I was interested in the subject and the discourse surrounding it, so I usually "passed" the first stage, with jokes turning into serious conversations regarding sexual practices, qualities, choices, availability, and price. However, the fact that I took notes and my eventual refusal to engage in paid sex were often met with dismay and discomfort. If I would have avoided the subject or presented a criti$\mathrm{cal} /$ moralistic position to begin with, it would probably be ok. But engaging in a conversation and asking for details that only practitioners would know, and later refuse to take part in the activity itself, was not only surprising but also perceived negatively by people who did not know me well. 
Several taboos were breached when eating jungle meat in Hoi An: the Buddhist prohibition to consume the flesh of wild animals, which may turn the eater into a wild beast; the public act of killing, which is a violent expression of power; and the public defiance of the law. The context of corruption and abuse of power exacerbated the transgression, while excessive drinking, extramarital erotic relations, and paid sex further removed the event from the realm of the normative into that of the extraordinary and forbidden.

At this point, I would like to address another important food taboo that was transgressed in these meals: the taboo on human flesh. As pointed out earlier, human flesh is one of the ten forbidden meats in Buddhism. It is also a universal taboo. The ethnographic data on cannibalism is very problematic and mostly unreliable but the few authoritative sources distinguish between endo and exo cannibalism, suggesting that much of it is ritual and internal-when some flesh of a deceased ancestor is consumed by relatives to ensure continuity. Ethnographic descriptions of such events detail the great difficulty and distress suffered by the participants, who often collapse vomiting by the end of the ritual.

In Hoi An, however, quite a few men with whom I discussed their food preferences responded to my question about their favorite meats by pointing out that they liked human flesh (thich thit ngươi). This remark was yet another word game where food and sex were interchanged: "I like human flesh" meant "I like sex", and the fact that human flesh is forbidden insinuated for the kind of sex these men were talking about: the forbidden kind of sex-with lovers, mistresses, and sex workers. In goat and jungle meat restaurants, forbidden meat and forbidden sex were reflections of each other, and both were practiced even though it was clear to all those involved that these were social and moral transgressions.

The point, of course, is that such transgressions were context dependent, relative, and flexible. People may argue that one should not eat jungle food, avoid cruelty toward animals, should not pay for the meals of corrupt officials to gain actual or potential benefits, be faithful to their spouses, and avoid paid sex. Yet the very same people, in specific circumstances and company, may be sympathetic and even enthusiastic about these practices. 


\section{Culinary Ambivalence and Cultural Intimacy}

Eating goat meat and jungle meat in Hoi An are ambiguous culinary practices. The men who partake in such meals are well aware that they are socially and morally problematic and may be illegal. At the same time, they find them very appealing. This ambivalence is the source of the unease and anxiety that were always felt when discussing these culinary practices and when partaking in them. The ad hoc solution for this anxiety may be found in the sense of cultural intimacy that prevails among the diners in these meals.

Cultural intimacy is "the recognition of those aspects of a cultural identity that are considered a source of external embarrassment but that nevertheless provide insiders with their assurance of common sociality" (Herzfeld 2005: 3). In other words, cultural intimacy prevails among members of a specific culture who partake and indulge in specific cultural activities, which they perceive as their own, but at the same time find them embarrassing and therefore actively hide them from outsiders.

The prime example Herzfeld uses is the Greek government's attempt to ban plate-breaking in restaurants that attract both locals and tourists: "not only is the practice 'not Greek' despite all the evidence to the contrary, but it is humiliating for some Greeks to realize that tourists - Northern Europeans especially - see this custom as quintessentially Greek. Plate smashing becomes a site of 'cultural intimacy' for Greeks in relation to German observers ... Whether Germans really do look down on Greeks for smashing plates does not matter; the intimacy that emerges in this context of self-recognition is decidedly Greek" (Shryock 2004: 10).

Another example Herzfeld uses is Cretan sheep theft. According to Herzfeld, sheep stealing, as well as many other illegal activities such as tax evasion, are vehemently denied in public contexts and during official interaction with state representatives, but are celebrated privately as representations of cultural traits that signal out Greek or Cretan (or a specific village) distinctiveness. In one instance, Herzfeld describes how the Cretan shepherds he was studying invited a police team investigating sheep theft to a lavish feast. Meal over, the shepherds informed the police officers that they have just eaten the evidence (i.e., the stolen sheep). 
Somewhat different from plate smashing, the Cretan state representatives took part in the cultural intimacy of the revelation, even though they were the target of the scam. The police officers were fooled into accomplishment, but in this apparently negative status, were accepted as peers with whom cultural intimacy may be shared.

Herzfeld discusses cultural intimacy and its manifestations on the national level (as in "Greeks" vs. "Germans"), or as a relationship between citizens and the state (as with the sheep thieves and police officers). My data suggests for further realms where cultural intimacy defines relations and shapes their content.

The first realm is that of gender. Dishes made of he-goat and jungle meat were "men only" affairs. Men consumed them in the company of other men in an explicit attempt to enhance their sexual prowess. The women who shared the space and, at times, the food were either mistresses, beer-girls, or sex workers. Wives and girlfriends were excluded from this space of cultural intimacy. In fact, in the presence of wives, female friends and female relatives, or in mixed-gender company, men would frown upon these meats and food venues or dismiss the food.

But the very same men would be much more enthusiastic in the company of other men or in a quite corner, away from women. The smile that often accompanied the discussion of he-goat meat and jungle meat among men was similar to the smile that accompanied conversations about extramarital affairs or paid sex, as well as discussions of illegal transactions of money in the form of bribe. Such smiles seemed to express a strong sense of ambivalence: I know it's wrong - but I love it; are you in it with me?

The second realm of cultural intimacy may be set between state officials and other men. Yet while Herzfeld depicts a scene where local farmers fooled the police officers into cultural intimacy, Hoianese officials established social bonds with other men in the setting of these culinary establishments, where partaking in dodgy activities (enhanced sexuality, extramarital relations), which were at times illegal (prostitution, forbidden kinds of meat, corruption, and bribe), set the ground for cultural intimacy among the co-diners. In these meals, cultural intimacy was the outcome of a shared sense of transgression: we are all naughty boys; we now know each other's secrets; we are all in it together. 
Cultural intimacy is therefore the remedy for the anxiety involved in the context of such socioculinary transgressions. This remedy, however, is context dependent and bound in space and time: it allows those men sharing cultural intimacy to temporarily inhibit their reservations, partake in the transgression, and indulge in it. However, in the presence of those with whom such sense of cultural intimacy is not possible (spouses or "official" girlfriends, mixed-gender groups, elders, and other people who may be critical of such transgressions), frequenting he-goat and jungle meat restaurants would be criticized, denied, or dismissed.

Finally, a word is due about the essence of food anxieties (see Ehlert and Faltmann, this volume). Usually, the material and practical dimensions of food anxieties are those highlighted in the public discourse and the academic research; the most immediate and common are unhygienic foods or those polluted by poisons that may affect the eaters' short- and long-term well-being. In this chapter I argue that food anxieties are always contextualized in social and cultural circumstances and that at times, perhaps often, have very little to do with material considerations or with the physical effect on the diners' bodies. Rather, food anxieties may emerge in situations where social norms are transgressed and where symbolic interpretations define the meanings of specific situations and interactions. They are, indeed, forbidden from the heart.

\section{Notes}

1. This tendency may be the outcome of the assumption that there is only one true god and that all other gods are false. This binary of "true" versus "false" evolves into an ever-expanding set of moral binaries: right and wrong, holy and profane, allowed and forbidden, and so on. In the culinary sphere, it is extended into the binaries of clean and polluted, or edible and taboo. These culinary binaries are central to monotheistic thought and practice no less than the binaries of life and death, men and women, good and evil, or nature and culture highlighted by Lévi-Strauss (1963, 1966). In non-monotheistic cultures such as Vietnam, these dichotomies are less clear-cut, and a more flexible and relativistic attitude prevails when it comes to the perception of death, gender, moral 
standards, and the place of humans in the cosmological order. This flexibility is also the rule in the culinary sphere. Perhaps, as my colleague Uri Shwed suggested, it is the other way round: a cultural tendency for binaries leads to monotheism and to total food prohibitions, while more flexible and relativistic cultures are susceptive to the multiplicity of gods and to laxer food regimes.

2. The term "old goat" in English and Hebrew stands for someone who is lecherous. It implies though that there are also "young goats", that is, acceptably libidinous young people. In any case, he-goat is associated with sexual desire in other cultures too.

3. http://www.inquisitr.com/1379070/little-tiger-vietnams-taste-for-catmeat/, sampled 13.12.16.

\section{References}

Adams, C.J., 2015. The sexual politics of meat: A feminist-vegetarian critical theory. London: Bloomsbury.

Avieli, N., 2012a. Dog meat politics in a Vietnamese town. Ethnology, 50, 1: 59-78.

Avieli, N. 2012b. Rice Talks: Food and Community in a Vietnamese Town. Bloomington: Indiana University Press.

Avieli N., 2014. Vegetarian Ethics and Politics in Postsocialist Vietnam. In Yuson Jung, Jakob Klein, and Melissa Caldwell (eds.) Ethical Eating in the Postsocialist and Socialist World. Berkeley: University of California Press. Pp. 144-166.

Bourdieu, P., 1984. Distinction: A social critique of the judgement of taste. Cambridge: Harvard University Press.

Calder, A. 1999. The Thrice Mysterious Taboo: Melville's Typee and the perception of culture. Representations 67: 27-43.

Mary, D. (1975). Implicit Meanings: essays in anthropology. London: Routledge and Kegan Paul.

Douglas, M. 2003 [1966]. Purity and danger: An analysis of concepts of pollution and taboo. London: Routledge.

Elias, N., 1978. The civilizing process. Vol. 1: The history of manners. New York: Pantheon.

Fiddes, N., 2004. Meat: A natural symbol. New York: Routledge. 
Gilmore, H., Schafer, C. and Halcrow, S., 2013. Tapu and the invention of the "death taboo": An analysis of the transformation of a Polynesian cultural concept. Journal of Social Archaeology, 13, 3: 331-349.

Harris, M., 1987. The Sacred Cow and the Abominable Pig: riddles of food and culture. Simon and Schuster.

Herzfeld, M., 1985. The Poetics of Manhood. Princeton: Princeton University Press.

Herzfeld, M., 2005. Cultural intimacy: Social poetics in the nation-state. New York: Routledge.

Herzfeld, M., 2009. Serving Ambiguity: Class and Classification in Thai Food at Home and Abroad. In Kim, K.O. ed., 2015. Re-orienting Cuisine: East Asian Foodways in the Twenty-first Century. New York and Oxford: Berghahn Books, 186-201.

Horton, P. and Rydstrom, H., 2011. Heterosexual masculinity in contemporary Vietnam: Privileges, pleasures, and protests. Men and Masculinities, 14(5), 542-564.

Jamieson, N.L., 1995. Understanding Vietnam. Berkeley: Univ of California Press.

Lévi-Strauss, C. 1963. Structural Anthropology. London: Basic Books.

Lévi-Strauss, C. 1966. The Culinary triangle. New Society, 8, 221: 937-940.

Lien, M. 2004. Dogs, Whales and Kangaroos: Transnational activism and food taboos. In Lien, M. and Nerlich, B. (eds.). The Politics of Food. London: Berg Publishers, pp. 179-199.

McNaIIy, S., 2003. Bia om and karaoke: HIV and everyday life in urban Vietnam. In Drummond, L.B.W. and Thomas, M. (eds.), 2003. Consuming Urban Culture in Contemporary Vietnam. London: Routledge Curzon.

Nguyen-vo, Thu-huong, 2008. The Ironies of Freedom: Sex, Culture, and Neoliberal Governance in Vietnam. Seattle: University of Washington Press.

Manderson, L., \& Mathews, M. 1981. Vietnamese behavioral and dietary precautions during pregnancy. Ecology of Food and Nutrition, 11(1), 1-8.

Mathews, M., \& Manderson, L., 1981. Vietnamese behavioral and dietary precautions during confinement. Ecology of Food and Nutrition, 11(1), 9-16.

Meyer-Rochow, V. B. (2009). Food taboos: their origins and purposes. Journal of Ethnobiology and Ethnomedicine, 5(1), 1.

Mintz, S.W. and Du Bois, C.M., 2002. The anthropology of food and eating. Annual review of anthropology, 31(1), 99-119.

Sachdev, P. S. 1989. Mana, Tapu, Noa: Maori cultural constructs with medical and psychosocial relevance. Psychological Medicine 19: 959-969. 
Sahlins, M.D., 1963. Poor man, rich man, big-man, chief: political types in Melanesia and Polynesia. Comparative studies in society and history, 5(3), 285-303.

Shirres, M.P. 1982. Tapu. The Journal of the Polynesian Society, 91, 1: 29-51.

Shryock, A., 2004. Off stagelon display: intimacy and ethnography in the age of public culture. Stanford: Stanford University Press.

Tambiah, S.J., 1969. Animals are good to think and good to prohibit. Ethnology, $8(4), 423-459$.

Twigg, J. (1983). Vegetarianism and the meanings in meat. In Murcott, A., 1983. The sociology of food and eating: essays on the sociological significance of food. Aldershot: Gower, 18-30.

Willard, B.E., 2002. The American story of meat: Discursive influences on cultural eating practice. The Journal of Popular Culture, 36(1), 105-118.

Yifa. (2002). The origins of Buddhist monastic codes in China: an annotated translation and study of the Chanyuan qinggui. University of Hawaii Press.

Open Access This chapter is licensed under the terms of the Creative Commons Attribution 4.0 International License (http://creativecommons.org/licenses/ by/4.0/), which permits use, sharing, adaptation, distribution and reproduction in any medium or format, as long as you give appropriate credit to the original author(s) and the source, provide a link to the Creative Commons licence and indicate if changes were made.

The images or other third party material in this chapter are included in the chapter's Creative Commons licence, unless indicated otherwise in a credit line to the material. If material is not included in the chapter's Creative Commons licence and your intended use is not permitted by statutory regulation or exceeds the permitted use, you will need to obtain permission directly from the copyright holder.

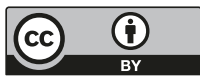

